\title{
Preparation and Characterization of Head-to-Head Polymer. I. Head-to-Head Poly(methyl cinnamate)
}

\author{
T. TANAKA and O. VogL \\ Polymer Science and Engineering, University of Massachusetts, \\ Amherst, Mass. 01002 U.S.A.
}

(Received March 12, 1974)

\begin{abstract}
Head-to-head $(\mathbf{H}-\mathbf{H})$ poly(methyl cinnamate) was obtained by alternating radical copolymerization of stilbene and maleic anhydride followed by esterification of the copolymer. The properties of the polymer were compared with head-to-tail $(\mathrm{H}-\mathrm{T})$ poly(methyl cinnamate). The $\mathbf{H}-\mathbf{H}$ polymer was more soluble in organic solvents, had a lower degradation temperature and higher degradation rate than the $\mathrm{H}-\mathrm{T}$ polymer. On pyrolysis, the main thermal degradation product of $\mathrm{H}-\mathrm{H}$ and $\mathrm{H}-\mathrm{T}$ polymers was methyl cinnamate. In addition, $\mathbf{H}-\mathbf{H}$ poly(methyl cinnamate) gave also small amounts of trans-stilbene and a mixture of dimethyl maleate and dimethyl fumarate.
\end{abstract}

KEY WORDS Head-to-Head Polymer / Alternating Copolymer /

Poly(methyl cinnamate) / Quantitative Esterification / Thermal

Degradation / TGA / Differential Scanning Calorimetry / Pyrolysis-

G.C. 1

Polymers prepared by bond opening polymerizations of $\alpha$-olefins, vinyl and acrylic monomers have mainly $\mathrm{H}-\mathrm{T}$ linkages in the polymer backbone chains ${ }^{1}$. The presence of $\mathrm{H}-\mathrm{H}$ linkages in such polymers prepared by a radical polymerization has been assumed to occur by a termination reaction caused by radical recombination. ${ }^{2}$

In addition, cases have become known where reverse monomer addition was responsible for the presence of up to $30 \%$ of $\mathrm{H}-\mathrm{H}$ linkages in the polymer chain. Most of the monomers which have detectable amounts of $\mathrm{H}-\mathrm{H}$ linkages in the polymer chain after radical polymerization have a halogen substituent, such as chlorine or fluorine atom attached to the carbon-carbon double bond. Examples for such monomers are vinyl chloride ${ }^{3}$, vinyl fluoride ${ }^{4}$, vinylidene fluoride $^{4}$ and chloroprene ${ }^{5}$. The amount of $\mathrm{H}-\mathrm{H}$ linkages can be varied in some cases with higher reaction temperatures commonly giving higher $\mathrm{H}-\mathrm{H}$ content in the polymer chain.

It was expected that pure $\mathbf{H}-\mathbf{H}$ polymers would have different and possibly useful new combinations of properties as compared to $\mathrm{H}-\mathrm{T}$ polymers.

Isolated efforts to obtain $\mathrm{H}-\mathrm{H}$ polymers have resulted in the preparation of $\mathrm{H}-\mathrm{H}$ polypropylene $^{6}$, poly(vinyl chloride $)^{7}$ and poly(methyl acrylate $)^{8}$.

$\mathrm{H}-\mathrm{H}$ polypropylene $\mathrm{e}^{6}$ was obtained by copolymerization of ethylene and 2-butene with coordination initiator with a large excess of 2-butene. Careful fractionation of the copolymer mixture was necessary to obtain a trace amount of copolymer, containing $50 \%$ of 2-butene, the $\mathrm{H}-\mathrm{H}$ polymer was analyzed but not characterized further.

$\mathrm{H}-\mathrm{H}$ poly(vinyl chloride) ${ }^{7}$ was obtained from polybutadiene by chlorine addition to the remaining double bonds of the polybutadiene. The chlorination had to be carefully studied to avoid chlorine substitution. Bailey ${ }^{7}$ found that $\mathrm{H}-\mathrm{H}$ poly(vinyl chloride) prepared by this route has a higher $T_{\mathrm{g}}$ than $\mathrm{H}-\mathrm{T}$ poly(vinyl chloride).

$\mathrm{H}-\mathrm{H}$ poly(methyl acrylate) was prepared from the well known alternating ethylene/maleic anhydride copolymer ${ }^{9,10}$ followed by esterification. This $\mathbf{H}-\mathbf{H}$ polymer was characterized to a limited extent and it had a higher $T_{\mathrm{g}}$ than the corresponding $\mathrm{H}-\mathrm{T}$ poly (methyl acrylate) ${ }^{8}$

In attempts to prepare $\mathrm{H}-\mathrm{H}$ polystyrene, Richards ${ }^{11-14}$ used a step growth polymerization with the styrene dimer dianion as the starting material and obtained polymers of relatively low molecular weight but with a structure that does not contain entirely $\mathrm{H}-\mathrm{H}$ linkages. 
In a study to determine the thermal stability of $\mathrm{H}-\mathrm{H}$ as compared to $\mathrm{H}-\mathrm{T}$ linkages in polystyrene, Grassie ${ }^{15}$ concluded that the $\mathrm{H}-\mathrm{H}$ linkages in polystyrene are of comparable thermal stability as are the $\mathrm{H}-\mathrm{T}$ linkages. He suggested that the $\mathrm{H}-\mathrm{H}$ linkages are not the weak links in the thermal degradation of polystyrene obtained by radical polymerization of styrene.

In this work, pure $\mathbf{H}-\mathbf{H}$ poly(methyl cinnamate) was prepared, characterized and some of its physical properties and the thermal degradation were studied.

\section{EXPERIMENTAL}

\section{Materials}

All chemicals except benzoyl peroxide were Eastman Kodak Co. chemicals.

Trans-stilbene was purified by recrystallization from dry ethanol and dried at $1 \mathrm{mmHg}$ overnight at room temperature prior to its use.

Maleic hydride $(10 \mathrm{~g})$ was dissolved in dry benzene $(100 \mathrm{~m} l)$ and pressure filtered. The solution was used directly for polymerization. Eastman's maleic anhydride contains a few percent of insoluble material, presumably maleic acid.

Azobisisobutyronitrile (AIBN) was purified by recrystallization three times from dry methanol $\left(10 \mathrm{~g}\right.$ AIBN in $50 \mathrm{ml}$ methanol at $35^{\circ} \mathrm{C}$, then cooled to $0^{\circ} \mathrm{C}$ yield 7.5 ) and dried at $0.1 \mathrm{mmHg}$ overnight at room temperature prior to its use.

Trans-methyl cinnamate $\left(\mathrm{mp} 37^{\circ} \mathrm{C}\right)$ was used without purification. Its purity was checked by G.C. (column; diisodecyl phthalate or SE-30 silicon gum rubber) prior to its use. Our methyl cinnamate had a level of impurities of about $0.1 \%$ which did not interfere with the polymerization.

Chloroform was washed with water, dried over calcium chloride and distilled from phosphorous pentoxide before use.

Dimethyl sulfate was used without purification.

Benzoyl peroxide (BPO) containing 22-\% water was obtained from Polysciences Inc. and recrystallized three times from dry ethanol (10-g BPOcontaining water dissolved in $200-\mathrm{m} l$ ethanol at $40^{\circ} \mathrm{C}$, then cooled to $0^{\circ} \mathrm{C}$, yield 6.0-g pure BPO). It was dried at $0.1 \mathrm{mmHg}$ overnight at room temperature before use.

\section{Copolymerization}

Trans-stilbene and maleic anhydride were copolymerized in a vacuum sealed polymerization tube by radical polymerization using AIBN as the initiator. A typical polymerization is given in the example.

Example. Maleic anhydride $(3.93 \mathrm{~g}, 40 \mathrm{mmol})$ was dissolved in $50-\mathrm{m} l$ benzene and filtered under a nitrogen atmosphere. Trans-stilbene (7.2 g, 40 $\mathrm{mmol}$ ) and AIBN (33 mg, $0.20 \mathrm{mmol}$ ) were added to the solution. The whole solution was charged into a $100-\mathrm{m} l$ polymerization tube, the tube was cooled in a dry ice-methanol bath and degassed at $0.1 \mathrm{mmHg}$. The degassing procedure was repeated three times. The tube was closed with a stop cock, disconnected from the vacuum line and warmed gradually to room temperature. Finally, the tube was sealed while the lower part of the tube was in a dry ice-methanol bath. The tube, properly shielded, was held in a conconstant temperature bath at $60^{\circ} \mathrm{C}$. After $2 \mathrm{hr}$, the tube was opened and the contents of the tube was poured into $500 \mathrm{ml}$ of dichloroethane to coagulate the polymer. The polymer was washed several times with dichloroethane, filtered and dried at $0.1 \mathrm{mmHg}$ at $50^{\circ} \mathrm{C}$, yield $2.5 \mathrm{~g}$. Additional examples of copolymerizations of stilbene and maleic anhydride in which solvent, initiator concentration and polymerization time were varied to achieve maximum yield and molecular weight are described in Table I.

\section{Esterification of Alternating Stilbene and Maleic Anhydride Copolymer}

Alternating stilbene-maleic anhydride copolymer $(2.5 \mathrm{~g})$ was dissolved in $330 \mathrm{ml}$ of aqueous 3- $N \mathrm{NaOH}$ solution and agitated at about $90^{\circ} \mathrm{C}$ for $1 \mathrm{hr}$. The suspension was diluted to about $1 l$ by adding distilled water. A clear solution of $\mathrm{H}-\mathrm{H}$ poly(sodium cinnamate) in excess sodium hydroxide was obtained. The solution was cooled to room temperature. Dimethyl sulfate $(200 \mathrm{~m} l$ which constitutes a large excess) was added to the solution with vigorous stirring. After $1 \mathrm{hr}$ the dimethyl sulfate layer which contained the esterified polymer was separated from the aqueous layer and $1 l$ of methanol was added to the dimethyl sulfate solution with stirring. A white polymer of $\mathrm{H}-\mathrm{H}$ poly(methyl cinnamate) precipitated. The $\mathrm{H}-\mathrm{H}$ poly(methyl cinnamate) 


\section{T. TANAKA and O. VoGL}

Table I. Copolymerization of trans-stilbene and maleic anhydridea

\begin{tabular}{|c|c|c|c|c|c|}
\hline $\begin{array}{c}\text { Experiment } \\
\text { No. }\end{array}$ & Solvent & $\begin{array}{l}\text { AIBN, } \\
\mathrm{mg}(\mathrm{mmol})\end{array}$ & $\begin{array}{l}\text { Polymerization } \\
\text { time, min }\end{array}$ & $\begin{array}{l}\text { Polymerization, } \\
\mathrm{g}(\%)\end{array}$ & $\eta_{\mathrm{sp}} / C^{\mathrm{b}}$ \\
\hline 1 & $\mathrm{CHCl}_{3}$ & $157 \quad(0.96)$ & 50 & $1.8(17)$ & 0.22 \\
\hline 2 & $\mathrm{CHCl}_{3}$ & $78.7(0.48)$ & 48 & 1.8 (17) & 0.32 \\
\hline 3 & $\mathrm{CHCl}_{3}$ & $19.7(0.12)$ & 70 & $1.8(17)$ & - \\
\hline 4 & $\mathrm{CHCl}_{3}$ & $8.2(0.05)$ & 23 & 10.7 (96) & 1.10 \\
\hline 5 & $\mathrm{CHCl}_{3}$ & $3.3(0.02)$ & 23 & $8.3(75)$ & 1.40 \\
\hline 6 & $\mathrm{CHCl}_{3}$ & $3.3(0.02)$ & 23 & $7.8(70)$ & 1.21 \\
\hline 7 & $\mathrm{C}_{6} \mathrm{H}_{6}$ & $41.0(0.25)$ & 2 & $2.3(21)$ & 0.62 \\
\hline 8 & $\mathrm{C}_{6} \mathrm{H}_{6}$ & $41.0(0.25)$ & 21 & 8.7 (77) & 0.60 \\
\hline 9 & $\mathrm{C}_{6} \mathrm{H}_{5} \mathrm{Cl}$ & $41.0(0.25)$ & 2 & $2.4(22)$ & 0.58 \\
\hline 10 & $\mathrm{C}_{6} \mathrm{H}_{5} \mathrm{Cl}$ & $41.0(0.25)$ & 23 & $9.4(85)$ & 0.60 \\
\hline
\end{tabular}

a Solvent amount, $50 \mathrm{ml}$; polymerization temperature, $60^{\circ} \mathrm{C}$; trans-stilbene-maleic anhydride, $3.92 \mathrm{~g}$ $(40 \mathrm{mmol}) / 7.2 \mathrm{~g}(40 \mathrm{mmol})$.

${ }^{\mathrm{b}}$ Measured as aqueous $\mathrm{H}-\mathrm{H}$ poly(sodium cinnamate); $0.2 \mathrm{~g} / \mathrm{d} l$ in $0.5-\mathrm{N} \mathrm{NaOH}$ aq soln at $30^{\circ} \mathrm{C}$.

Table II. Analytical data for $\mathrm{H}-\mathrm{H}$ poly(methyl cinnamate)

\begin{tabular}{|c|c|c|c|c|c|c|c|}
\hline \multicolumn{2}{|c|}{ Polymer } & \multirow{2}{*}{$\eta_{\mathrm{sp}} / C^{\mathrm{a}}$} & \multicolumn{3}{|c|}{ Elemental analysis, $\%$} & \multirow{2}{*}{$\begin{array}{l}\text { Residual } \\
-\mathrm{COOH}^{\mathrm{b}}\end{array}$} & \multirow{2}{*}{$\begin{array}{l}\mathrm{Na}^{\mathrm{c}} \text { per } \\
\text { total }-\mathrm{COO}\end{array}$} \\
\hline Esterified & Original & & $\mathrm{C}$ & $\mathbf{H}$ & $\mathbf{O}$ & & \\
\hline E-1 & 1 & 0.51 & 73.0 & 6.10 & 19.9 & - & - \\
\hline $\mathrm{E}-2$ & 2 & 0.67 & 74.2 & 6.82 & 19.0 & - & - \\
\hline E-3 & 3 & 0.88 & 72.5 & 6.35 & 21.0 & - & - \\
\hline $\mathrm{E}-4$ & 4 & 1.38 & 73.7 & 6.33 & 19.9 & - & - \\
\hline $\mathrm{E}-5$ & 5 & 0.89 & 73.8 & 6.66 & 19.9 & $\sim 0.2 \%$ & $<0.2 \%$ \\
\hline \multirow[t]{2}{*}{ E-6 } & 6 & 1.10 & 73.8 & 6.35 & 19.9 & $\sim 0.2 \%$ & $<0.2 \%$ \\
\hline & & Theory & 74.0 & 6.17 & 19.8 & 0 & 0 \\
\hline
\end{tabular}

a $0.2 \mathrm{~g} / \mathrm{d} l$ in dimethyl formamide at $30^{\circ} \mathrm{C}$.

b Potentiometric titration in dimethyl formamide with $0.1-\mathrm{N} \mathrm{CH}_{3} \mathrm{ONa}$.

c Atomic absorption of ash after polymer combustion.

Table III. Bulk polymerization of methyl cinnamate ${ }^{a}$

\begin{tabular}{|c|c|c|c|}
\hline $\begin{array}{l}\text { Methyl cynnamate, } \\
\text { g (mmol) }\end{array}$ & Initiator, $\mathrm{g}$ (mmol) & Polymer yield, g (\%) & $\eta_{\mathrm{sp}} / C^{\mathrm{b}}$ \\
\hline $32.4(200)$ & AIBN $0.024(0.15)$ & $0.5 \quad(1.5)$ & - \\
\hline $32.4(200)$ & BPO $0.242(1.0)$ & $2.5 \quad(7.6)$ & 0.31 \\
\hline $16.2(100)$ & $0.800(3.3)$ & $4.0(12.3)$ & 0.19 \\
\hline
\end{tabular}

a Polymerization temperature, $60^{\circ} \mathrm{C}$; polymerization time, $100 \mathrm{hr}$.

b $0.2 \mathrm{~g} / \mathrm{d} l$ in $\mathrm{CF}_{3} \mathrm{COOH}$ at $30^{\circ} \mathrm{C}$.

was analyzed for carbon, hydrogen and residual sodium. Residual free $-\mathrm{COOH}$ groups were analyzed by potentiometric titration. The maximum detectable amount given in the table represent the error limit of our analysis. All analytical data are given in Table II.

\section{Polmerization of Methyl Cinnamate}

Trans-methyl cinnamate was polymerized by radical polymerization in a vacuum sealed polymerization tube in bulk using BPO or AIBN as an initiator (Table III).

Thermal degradation of all polymers (TGA) 
Head-to-Head Polymers I.

was carried out in a nitrogen atmosphere using a Perkin-Elmer TGS-1 thermobalance. Most results are reported as DTG (differential thermogravimetric analysis ${ }^{16}$ ) at a programmed temperature increase of $5^{\circ} \mathrm{C} / \mathrm{min}$.

A Perkin-Elmer DSC-1B differential scanning calorimeter was used for the measurement of the polymer's thermal behavior.

Polymers were pyrolysed in a Hewlett Packard Model 80 Pyrolyser. The polymer samples were held in a $\mathrm{Pt}-\mathrm{Rh}$ electrode and the desired pyrolysis temperature achieved by applying the appropriate voltage; the electrode was heated for about $10 \mathrm{sec}$. The sample size for pyrolysisG.C. was about $1 \mathrm{mg}$. The pyrolysis products were directly passed into a Varian Aerograph Model 920 and analyzed.

\section{RESULTS AND DISCUSSION}

The copolymerization of trans-stilbene and maleic anhydride gives only alternating copolymer. Under normal copolymerization conditions as we have used, homopolymerization of stilbene or maleic anhydride does not occur. This reaction has been studied in the past by several workers, ${ }^{17-19}$ firstly, as early as 1930 by J. Wagner Jauregg. ${ }^{17}$ The copolymer obtained was assumed to be an alternating copolymer; it was insoluble and of unknown molecular weight. The copolymerization between trans-stilbene and maleic anhydride was recently reinvestigated at low temperature $^{19}$ and a polymer soluble in tetrahydrofuran was obtained; it was suggested that in earlier copolymerizations; crosslinking was the reason why earlier products were insoluble. We have no reason to believe that crosslinking had occurred in our experiments and we believe the insolubility of our copolymer is based on by high molecular weight.

It should also be pointed out that the transstilbene and maleic anhydride copolymerization has been used as an example in the controversy of the initiation or propogation of the polymerization involving charge-transfer complexes. This latter problem is not relevant to this paper.

It was the purpose of this paper to prepare trans-stilbene and maleic anhydride alternating copolymers and to transform these polymers into poly(methyl cinnamate).

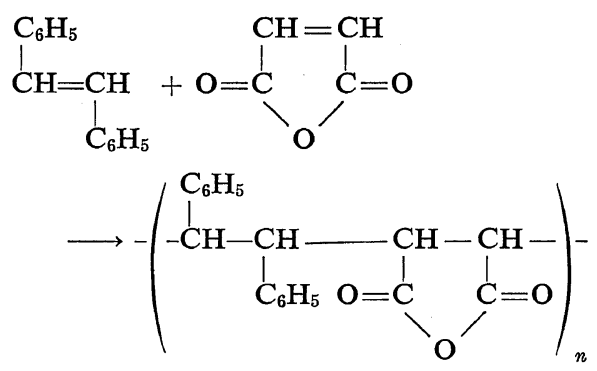

A number of polymerizations were carried out in benzene and chloroform as the solvent using AIBN as the initiator (Table I). In all cases the same copolymers were obtained. It was insoluble in all solvents tried but dissolved readily in aqueous $3-N$ sodium hydroxide at $90^{\circ} \mathrm{C}$ in $1 \mathrm{hr}$ to form the sodium salt of $\mathrm{H}-\mathrm{H}$ poly(cinnamic acid). Our trans-stilbene-maleic anhydride copolymers show the normal absorption bands in the infrared expected for such a copolymer (Figure 1a). No unusual bands, particularly carbonyl bands other than anhydride carbonyls, were noticeable in the infrared. These carbonyl bands would be easily detectable even at levels of 3 to $5 \%$ in addition to the anhydride carbonyl bands and would represent an indication of crosslinking in the polymer. Because of our specific objective of preparing a poly(methyl cinnamate), we did not investigate in detail the possibility of trace amounts of branching in our polymer. However, we believe that our polymer, based on the absence of any unusual carbonyl absorptions and on the ready solubility in sodium hydroxide is not branched but of high molecular weight as other measurements will show. Rigorous examinations of the linearity of our trans-stilbene and maleic anhydride copolymer have not been made.

Several methods have been attempted for the transformation of the anhydride into an ester group. It should be emphasized that it was desirable to have a purity of ester groups of more than $99.8 \mathrm{~mol} \%$ because among other investigations, the investigation of the thermal degradation was to be attempted and for this purpose an almost $100-\%$ purity of ester groups without free acid groups is necessary. Otherwise, thermal degradation could start from a weak point within the polymer chain.

The transformation of the polyanhydride into 


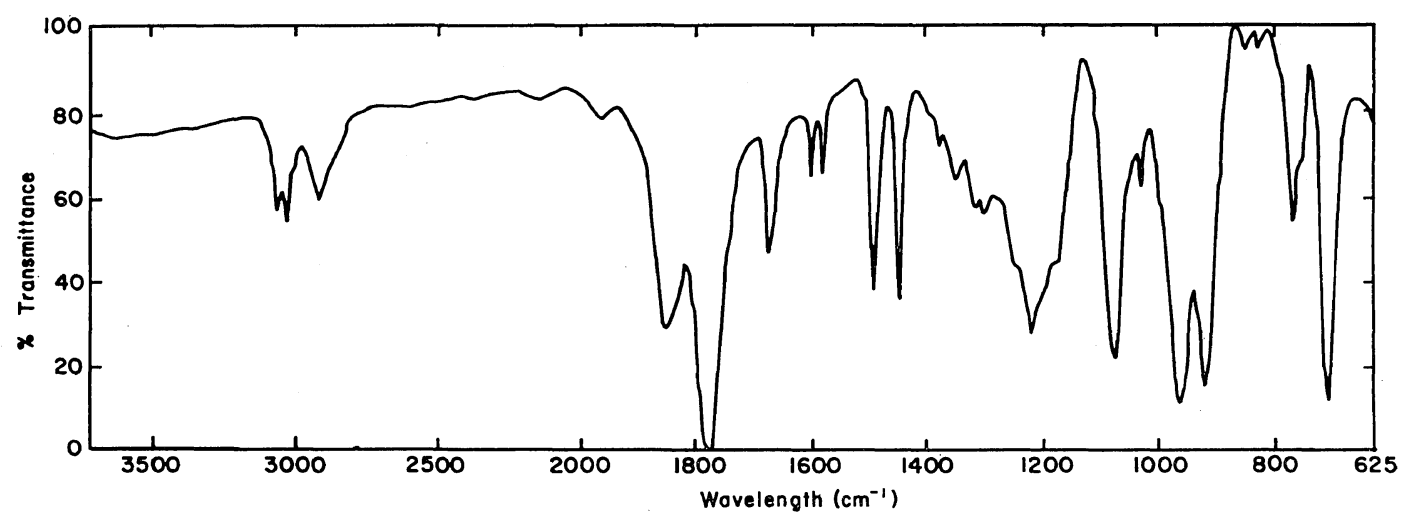

Figure 1a. IR spectrum of trans-stilbene and maleic anhydride copolymer-(KBr).

the sodium salt of poly(cinnamic acid) followed by methylation with dimethyl sulfate was found to be the most convenient technique for complete esterification.

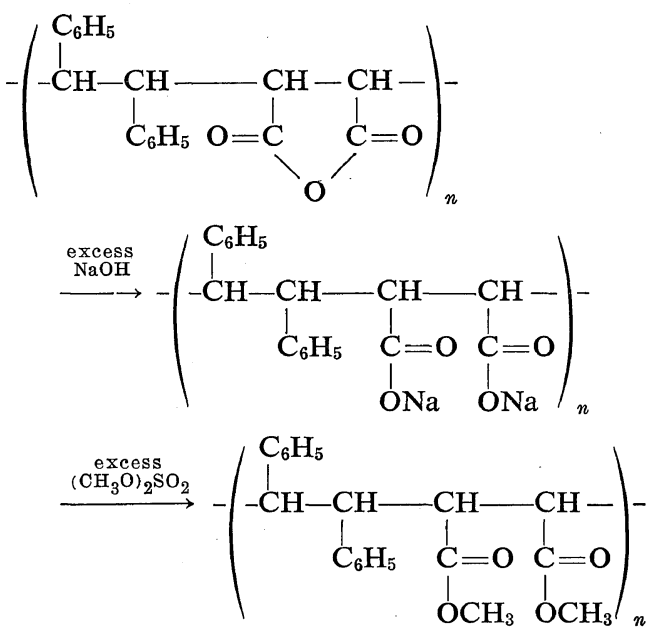

Alternate techniques for the preparation of poly(methyl cinnamate) from alternating stilbenemaleic anhydride copolymer by attempted direct esterification of the anhydride groups were not successful. They included treatment of the initial copolymer with methanol or ethanol and sulfuric acid, methanol alone, and diazomethane under various conditions. The reason for the failure of alternating stilbene-maleic anhydride copolymer to react was its insolubility in all media. Should it be possible to find an appropriate solvent there is no reason to believe that the esterification of the anhydride could not be readily achieved by means other than those described in this paper.

The elemental composition of $\mathrm{H}-\mathrm{H}$ poly(methyl cinnamate) was confirmed by elemental analysis (Table II). The polymer is an amorphous powder which, according to the X-ray diffraction pattern, does not give any indication of crystallinity but only shows an amorphous halo. It is soluble in trifluoroacetic acid, in pyridine at room temperature but also in dimethyl formamide, dimethyl acetamide and also chlorobenzene at somewhat elevated temperatures at concentrations of about 3 to $5 \%$.

As indicated in the infrared spectrum (Figure 1b), H-H poly(methyl cinnamate) does not have any free acid, acid salt or anhydride left in the polymer.

This has been confirmed by careful studies for the presence of metal (from the sodium salt) but also by acid titration directed at the detection of small amounts (less than 1\%) of carboxylic acid groups in the polymer at an accuracy of $\pm 0.1-\% \mathrm{COOH}$ groups. As indicated in Table II less than $0.2 \%$ of free carboxyl groups are left in the polymer.

Initital work has been done on the NMR spectrum of $\mathrm{H}-\mathrm{H}$ poly(methyl cinnamate). This work was done at room temperature in trifluoroacetic acid using a $60-\mathrm{MHz}$ spectrometer. This resolution and the room temperature study naturally does not give any indication of the stereochemistry of the polymer, however, it does show that the amount of phenyl protons (between 6 and $7 \mathrm{ppm}$ ) equals the sum of four methine protons and the 6 protons from the two methoxy groups of the ester group which are overlapping 


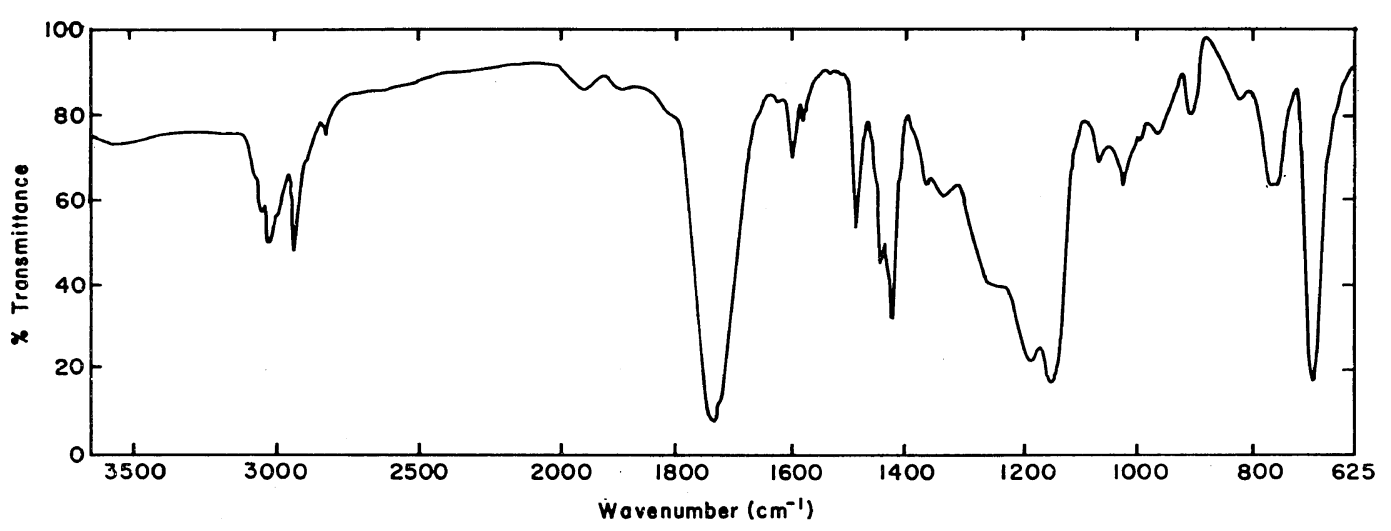

Figure 1b. IR spectrum of $\mathrm{H}-\mathrm{H}$ poly(methyl cinnamate)-(KBr).

at a chemical shift between 1.5 and $3.5 \mathrm{ppm}$. More extensive work on the stereochemistry of this polymer is planned in the future together with the study of the stereochemistry of other $\mathrm{H}-\mathrm{H}$ polymers by detailed NMR spectroscopy.

A study of the thermal behavior of this polymer by differential scanning calorimetry (DSC) at a heating rate of $5^{\circ} \mathrm{C}$ per minute indicated no peak which could be attributable to a glass transition temperature $\left(T_{\mathrm{g}}\right)$. However, noticeable decomposition starts from $330^{\circ} \mathrm{C}$.

The inherent viscosity of $\mathrm{H}-\mathrm{H}$ poly(methyl cinnamate) also sheds some light on the initial polymerization of trans-stilbene and maleic anhydride as can be seen in Table II. This assumes that no alterations have occurred during the saponification of the anhydride and the esterification of poly(sodium cinnamate).

The molecular weight of poly(methyl cinnamate) and poly(cinnamic acid) was measured by measuring the inherent viscosity of the appropriate solutions, sodium hydroxide solution for poly(cinnamic acid) (Table I) and DMF solution of poly(methyl cinnamate) (Table II). By implication, this molecular-weight measurement also suggests a minimum molecular weight for the initial trans-stilbene maleic anhydride copolymer.

The molecular weight of the initial polymer as judged by the molecular weight of $\mathrm{H}-\mathrm{H}$ poly(methyl cinnamate) which was estimated by measuring the inherent viscosity of the latter indicates the following relationship. The molecular weight of the trans-stilbene/maleic anhydride sopolymer is not affected by the reaction time but as expected, is affected by the ratio of initia- tor to monomer concentration or by the reaction temperature. At a lower ratio of initiator to monomer the molecular weight is higher as is the molecular weight higher in the case of lower reaction temperature.

It was necessary to prepare $\mathrm{H}-\mathrm{T}$ poly(methyl cinnamate) in order to have a proper comparison of $\mathrm{H}-\mathrm{H}$ with $\mathrm{H}-\mathrm{T}$ polymers. Table III shows the results of our polymerizations of methyl cinnamate with radical initiators. We believe that these polymers have mainly $\mathbf{H}-\mathbf{T}$ linkages in the backbone structure of the polymer. $\mathrm{H}-\mathbf{T}$ poly(methyl cinnamate) is soluble only in trifluoroacetic acid and dichloroacetic acid, in other words, it is much less soluble than the $\mathrm{H}-\mathrm{H}$ poly(methyl cinnamate) described above, although there is no apparent difference in the molecular weights of the two types of polymers.

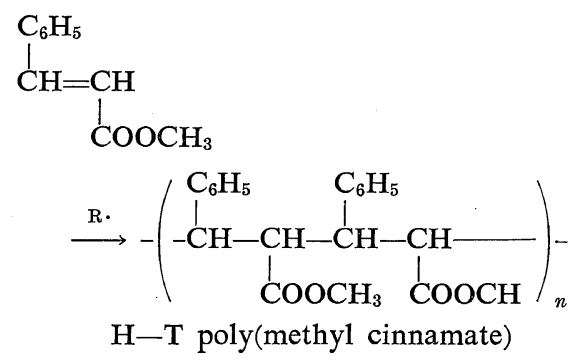

H-T poly(methyl cinnamate) shows an infrared spectrum (Figure 1c) containing the typical ester and phenyl frequencies. The NMR spectrum were taken in fluoroacetic acid at room temperature. It is similar but significantly different from the NMR spectrum of $\mathrm{H}-\mathrm{H}$ poly(methyl cinnamate). The methyl protons have 


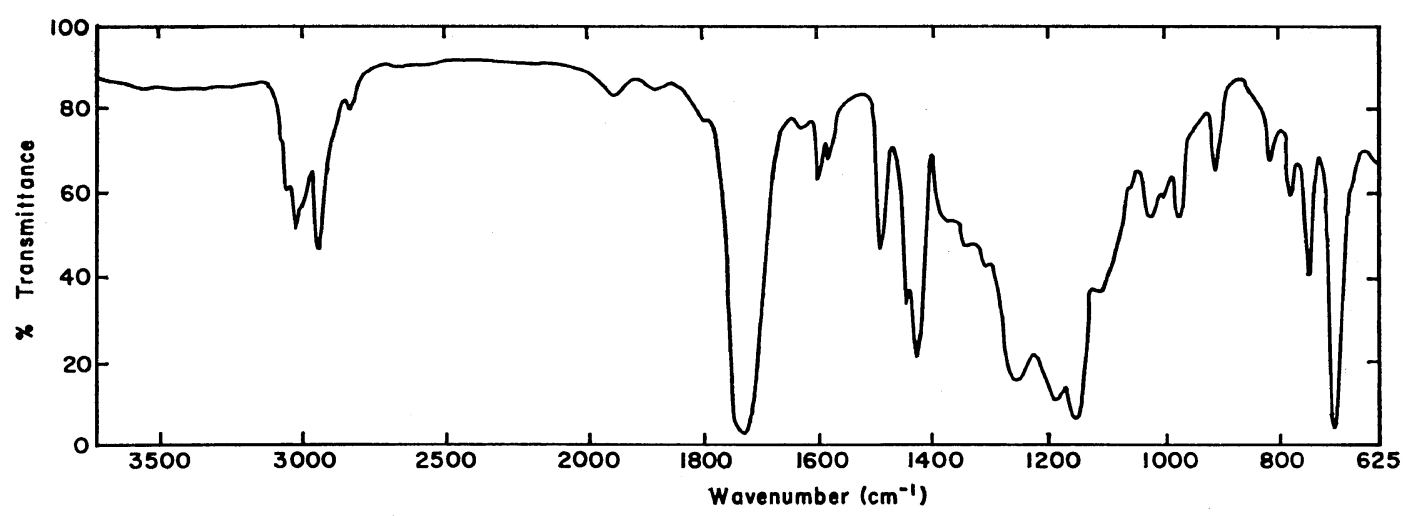

Figure 1c. IR spectrum of $\mathrm{H}-\mathrm{T}$ poly(methyl cinnamate)-(KBr).

a broad chemical shift from the ester methoxy group range peaking near $3.3 \mathrm{ppm}$ rather than the $2.8 \mathrm{ppm}$ seen in the $\mathrm{H}-\mathrm{H}$ polymer. On the other hand, phenyl protons have their chemical shift between 5.3 and $7 \mathrm{ppm}$. The ortho protons are distinguishably separated in the case of the $\mathrm{H}-\mathrm{T}$ polymer. Methine and methoxyl proton are overlapping between 1.5 and $3.5 \mathrm{ppm}$. The area under the curve of the phenyl protons is equal to that of the sum of the methine and methoxy protons indicating the correctness of the proposed structure of $\mathrm{H}-\mathrm{T}$ poly(methyl cinnamate).

$\mathrm{H}-\mathrm{T}$ poly(methyl cinnamate) is amorphous according to X-ray diffraction studies and the DSC analysis which was carried out under nitrogen at $5^{\circ} \mathrm{C} / \mathrm{min}$ showed no peak up to $360^{\circ} \mathrm{C}$ after which a vigorous decomposition pattern is noticeable.

$\mathrm{H}-\mathrm{T}$ as well as $\mathrm{H}-\mathrm{H}$ poly(methyl cinnamate) degrades primarily to methyl cinnamate; this is a rather remarkable result. It is, of course, expected that $\mathrm{H}-\mathrm{T}$ poly(methyl cinnamate) degrades to monomer because addition polymers which are highly substituted on the $\mathrm{C}-\mathrm{C}$ backbone particularly if they have 2 substituents on one C-atom degrade preferentially to monomer rather than to low- and high-molecular-weight fragments.

In the case of the $\mathrm{H}-\mathrm{H}$ polymer, the main degradation product is also methyl cinnamate although about $20 \%$ of the degradation leads to stilbene and dimethyl maleate.

Much of our pyrolysis was done by pyrolysisG.C. The polymers were pyrolized near the maximum degradation temperature determined by DTG and the results are shown in Figure 2 . The actual molar ratios of pyrolysis products are given in Table IV.

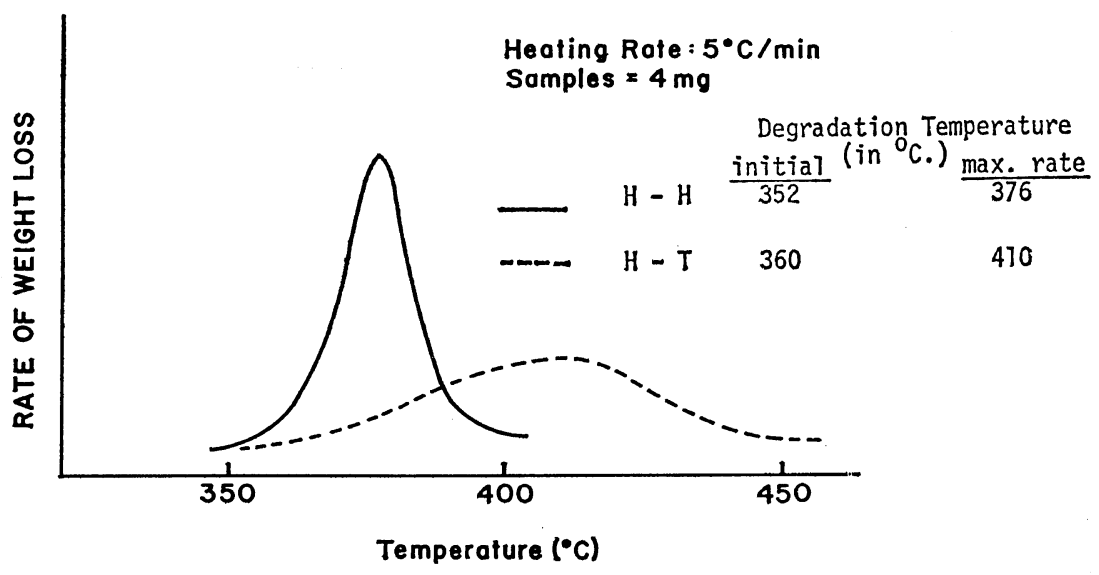

Figure 2. Degradation rate of polymers by TGA. 
Head-to-Head Polymers I.

Table IV. Relative molar ratios of pyrolysis products ${ }^{\mathrm{a}}$

\begin{tabular}{cccccrrr}
\hline Polymer & $\mathrm{CO}_{2}$ & $\mathrm{MeOH}$ & Acetone & DMM and DMFu & MC & STB \\
\hline E-6 $(\mathrm{H}-\mathrm{H})$ & $\sim 4$ & $\sim 0$ & 1.8 & 18 & 90 & 18 \\
P-16 (H-T) & $\sim 10$ & 10 & 2.0 & 0 & 100 & 0 \\
\hline
\end{tabular}

a DMM, dimethyl maleate; DMFu, dimethyl fumarate; MC, methyl cinnamate; STB, stilbene.

b $\mathrm{DMM} / \mathrm{DMFu}, 1.3$.

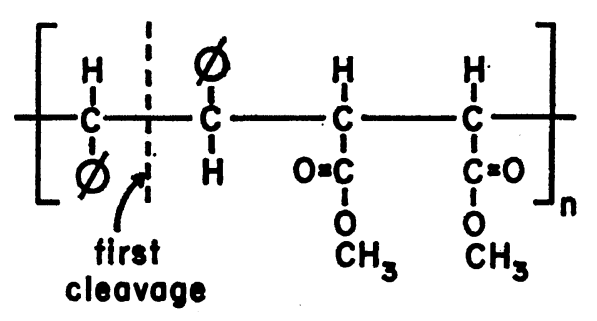

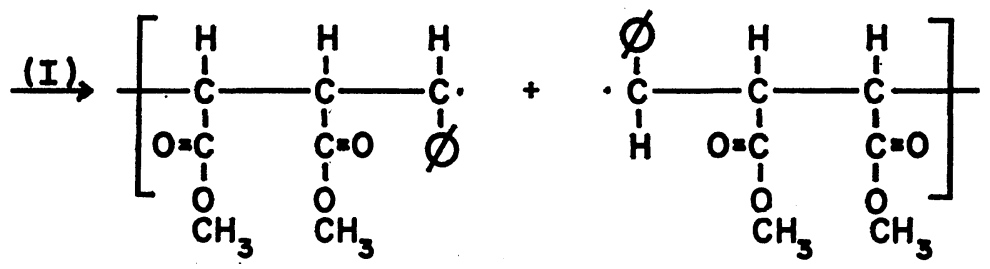

(A)

(B)

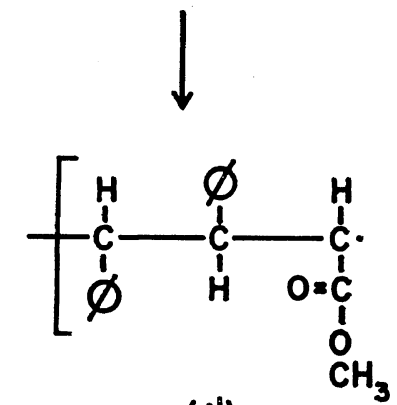

(A)<smiles>CO[C@H](C)C(=O)C1CCC1</smiles>

(B')<smiles>COC(=O)C=CO</smiles><smiles>COC(=O)C=CO</smiles>

Figure 3a. Degradation of $\mathrm{H}-\mathrm{H}$ PMC. 
At $350^{\circ} \mathrm{C}$ in a helium atmosphere the main product of the degradation is methyl cinnamate. As indicated above, some degradation to stilbene and dimethyl maleate of dimethyl fumarate also occurs in the degradation of $\mathbf{H}-\mathrm{H}$ poly(methyl cinnamate).

From the thermal degradation pattern and the degradation products it is not possible to deduce the stereochemistry of the original $\mathrm{H}-\mathrm{H}$ poly(methyl cinnamate). The degradation results should be compared with detailed NMR evidence when it becomes available. The significance of our degradation results is in the case of fragmentation and the simplicity of the fragmentation products.

Only one of the stilbene isomers was present after pyrolysis trans-stilbene. The fraction containing the unsaturated $\mathrm{C} 4$ esters contained both dimethyl maleate and dimethyl fumarate as seen in Table IV.

From UV spectroscopy of the dimethyl maleate and dimethyl fumarate mixture (which had been worked out many years ago) it could be ascertained that our mixture contained dimethyl maleate and dimethyl fumarate in a -1.3 molar ratio. As a comparison the $D_{245 \mathrm{~nm}}$ and $D_{264.5 \mathrm{~nm}}$ bands of the ultraviolet were used to distinguish between the two esters. Earlier, Kistiakowsky ${ }^{20}$ had studied the thermal isomerization equilibrium of dimethyl maleate and dimethyl fumarate and he found that this ratio was smaller than unity, in other words, the dimethyl fumarate is favored

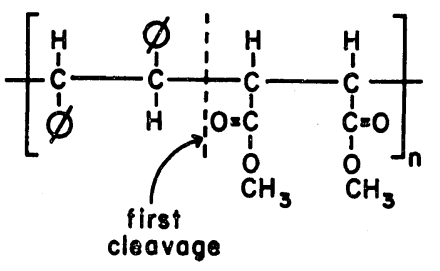

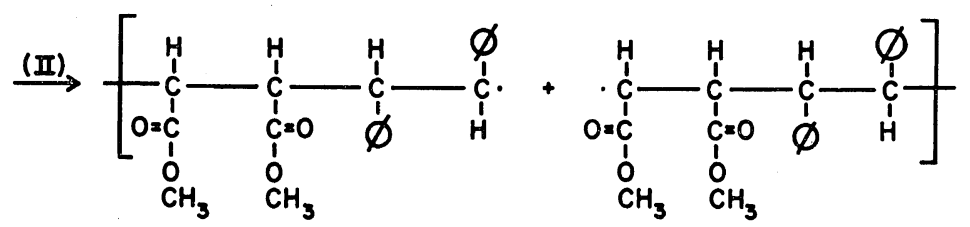

(A)

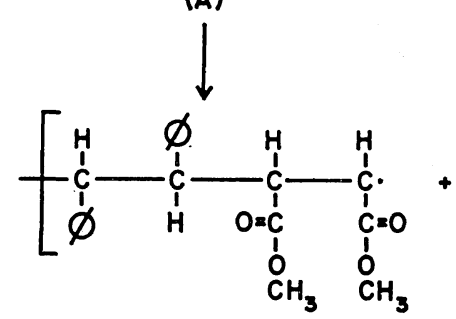

$\left(A^{\prime}\right)$

$A=B^{\prime}$
$B=A^{\prime}$
(B)

(B')

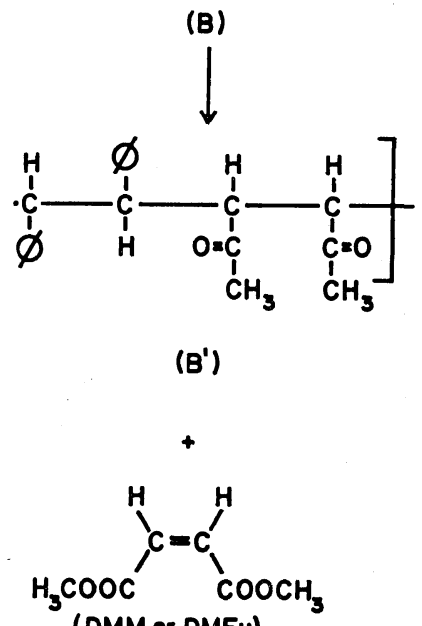<smiles>O=CC=O</smiles>

(STB)
(DMM or DMFU)

Figure 3b. Degradation of $\mathrm{H}-\mathrm{H}$ PMC. 
in the equilibrium condition. However, Kistiakowsky used equilibrium conditions (long times at $300^{\circ} \mathrm{C}$ ) while in our case the pyrolysis time is approximately $10 \mathrm{sec}$; this may be too short to attain equilibrium.

On the basis of these degradation results, we suggest that the $\mathrm{H}-\mathrm{H}$ and $\mathrm{H}-\mathrm{T}$ poly(methyl cinnamate) degradation is initiated by random cleavage of the polymer chain. From the maximum temperature of degradation (Figure 2) it is indicated that activation energy of degradation is lower in the case of $\mathrm{H}-\mathrm{H}$ as it is for $\mathrm{H}-\mathrm{T}$ polymers. In the case of $\mathrm{H}-\mathrm{T}$ poly(methyl cinnamate) only one kind of bond (disregarding the stereochemistry at this time) can be broken by random cleavage of the polymer chain. cleavage of the polymer chain. In the case of $\mathrm{H}-\mathrm{H}$ poly(methyl cinnamate) three kinds of linkage can be broken (again disregarding stereochemistry) (Figure 3). These three linkages are: the $\mathrm{C}-\mathrm{C}$ bond between two carbon atoms each having a phenyl substituent (Figure 3a), the $\mathrm{C}-\mathrm{C}$ bond between two carbon atoms each having a carbomethoxy substituent (Figure 3a) and the $\mathrm{C}-\mathrm{C}$ bond between two carbon atoms one having a phenyl substituent and one having a carbomethoxy substituent (Figure 3b).

It is intersting to speculate about the $\mathrm{H}-\mathrm{H}$ polymer degradation which leads to monomer. Clearly, after the loss of one monomer unit the degrading polymer radical is different from the previous one and we must consider a two step process for this degradation. The difference in rate of each of these two steps can be very significant and seems to depend very much upon the stability of the individual degrading radical. ${ }^{21}$

Acknowledgement. We are grateful to Mitsubishi Chemical Companies for their support and their permission to one of us to carry out this work at the University of Massachusetts. Additional support for this work was obtained from the U.S. National Science Foundation.

\section{REFERENCES}

1. P. J. Flory, "Principles of Polymer Chemistry," Cornell University Press, Ithaca, N. Y., 1953.

2. J.C. Bevington, "Radical Polymerization," Academic Press, New York, N.Y., 1961, p 148.

3. T. Otsu, A. Shimizu, and M. Imoto, J. Polym. Sci., Part A, 3, 615 (1965).

4. C. W. Wilson, and E. R. Santee, Jr., ibid., Part C, 8, 97 (1965).

5. C. A. Hargreaves IV. and D. C. Thompson, Encycl. Polym. Sci. Technol., 3705 (1964).

6. G. Natta, G. Dall'Asta, G. Mazzanti, I. Pasquon, A. Valvassori, and A. Zambelli, J. Amer. Chem. Soc., 83, 3343 (1961).

7. F. E. Bailey, Jr., J. P. Henry, R. D. Lundberg, and J. M. Whelan, J. Polym. Sci., Part B, 2, 447 (1964).

8. T. Otsu, S. Aoki, and R. Nakatani, Makromol. Chem., 134, 331 (1970).

9. R. S. Towne, U.S. Patent 2744098 (1956).

10. J.H. Johnson and J. R. Schefgen, "Macromolecular Syntheses," Vol. 1, C. G. Overberger, Ed., John Wiley and Sons, Inc., New York, N. Y., 1963.

11. D. H. Richards and N. F. Scilly, Chem. Commun., 1515 (1968).

12. D. H. Richards, N.F. Scilly, and Miss F. Williams, Polymer, 10, 603 (1969).

13. D. H. Richards, S. M. Hutchison, and N. F. Scilly, ibid., 10, 611 (1969).

14. D. H. Richards and N. F. Scilly, British Patent 1300384 (1972).

15. G. G. Cameron and N. Grassie, Makromol. Chem., 51, 130 (1962).

16. O. Vogl, V. Ivansons, H. C. Miller, and H.W. Williams, J. Macromol. Sci., A2, 175 (1968).

17. J. Wagner-Jauregg, Chem. Ber., 63, 3213 (1930).

18. F. M. Lewis and F. R. Mayo, J. Amer. Chem. Soc., 70, 1533 (1948).

19. M. L. Hallensleben, Eur. Polym. J. 9, 227 (1973).

20. M. Nelles and G. B. Kistiakowsky, J. Amer. Chem. Soc., 54, 2208 (1932).

21. C. H. Bamford, "The Kinetics of Vinyl Polymerization by Radical Mechanism," Butterworth Scientific Publication, London, 1958. 